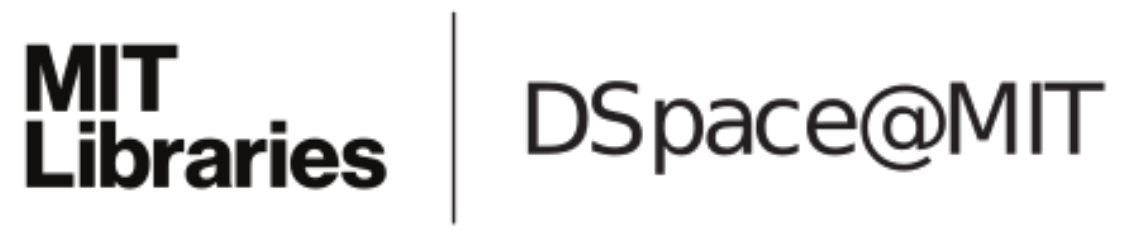

\author{
MIT Open Access Articles
}

An epigenetic clock controls aging

The MIT Faculty has made this article openly available. Please share how this access benefits you. Your story matters.

Citation: Mitteldorf, Josh. "An Epigenetic Clock Controls Aging." Biogerontology 17.1 (2016): 257265.

As Published: http://dx.doi.org/10.1007/s10522-015-9617-5

Publisher: Springer Netherlands

Persistent URL: http://hdl.handle.net/1721.1/105831

Version: Author's final manuscript: final author's manuscript post peer review, without publisher's formatting or copy editing

Terms of Use: Article is made available in accordance with the publisher's policy and may be subject to US copyright law. Please refer to the publisher's site for terms of use. 


\title{
An epigenetic clock controls aging
}

\author{
Josh Mitteldorf $\mathbb{D}$
}

Received: 25 December 2014/ Accepted: 7 October 2015/Published online: 25 November 2015

(C) Springer Science+Business Media Dordrecht 2015

\begin{abstract}
We are accustomed to treating aging as a set of things that go wrong with the body. But for more than twenty years, there has been accumulating evidence that much of the process takes place under genetic control. We have seen that signaling chemistry can make dramatic differences in life span, and that single molecules can significantly affect longevity. We are frequently confronted with puzzling choices the body makes which benefit neither present health nor fertility nor long-term survival. If we permit ourselves a shift of reference frame and regard aging as a programmed biological function like growth and development, then these observations fall into place and make sense. This perspective suggests that aging proceeds under control of a master clock, or several redundant clocks. If this is so, we may learn to reset the clocks with biochemical interventions and make an old body behave like a young body, including repair of many of the modes of damage that we are accustomed to regard as independent symptoms of the senescent phenotype, and for which we have assumed that the body has no remedy.
\end{abstract}

Keywords Senescence - Programmed aging · Epigenetic $\cdot$ Evolution $\cdot$ Life history $\cdot$ Gene expression

J. Mitteldorf ( $\square)$

Department of EAPS, MIT, Cambridge, MA, USA

e-mail: josh@mathforum.org

\section{Introduction}

Reasons to believe that aging derives from a genetic program

Since the pioneering work of Medawar (1952) and Williams (1957), it has become customary to understand the phenotypes of aging as failures of homeostasis in the body. Where the body has clearly made metabolic choices that hasten its demise, we look for tradeoffs and hidden benefits. Sometimes the tradeoffs and benefits are obvious, but when we cannot find them, we assume nevertheless that they must exist.

But a number of trends in recent decades suggest that aging is an independent adaptation, and that destruction of the body is proceeding under full control of the genome.

- The genetic basis for aging is conserved across such great spans of evolutionary distance (Guarente and Kenyon 2000; Kenyon 2001) as to render pleiotropy an implausible explanation, and mutational load an irrelevance.

- Animals are able to extend life span under some conditions of hardship and environmental challenge, including caloric restriction (Calabrese and Baldwin 1998; Calabrese 2005; Masoro 2005, 2007). Frequently the life extension comes at minimal cost in fertility (Flatt 2009), especially for males (Weindruch and Walford 1988; Masoro 2003). The ability of the body to extend life span 
under stress hints that, in the absence of stress, the body harbors a latent capacity for longer life that is not activated because of genetic programming (Mitteldorf 2001).

- Evidence for pleiotropy of known aging genes is weak (Kirkwood 2005; Blagosklonny 2010). In fact, pleiotropic benefits have only been discovered for a small proportion of genes that shorten life span (Curtsinger et al. 1995; Stearns 2000), and several examples are documented in which a wild-type allele shortens life span and also lowers fertility (Spitze 1991; Bronikowski and Promislow 2005; Hanson and Hakimi 2008).

- The high fitness cost of aging in the wild (Ricklefs 1998; Bonduriansky and Brassil 2002; Nussey et al. 2012; Jones et al. 2014) is inconsistent with the once-dominant Mutation Accumulation theory, and steepens the challenge to the pleiotropic theories as well.

- The existence of programmed aging in protists, in the form of cellular senescence (Clark 1999, 2004) defies classical evolutionary theory. The association of cellular senescence with increased mortality in humans (Cawthon et al. 2003; Fitzpatrick et al. 2007; Kimura et al. 2008) is prima facie evidence for a form of programmed death. The classical explanation is that cellular senescence offers protection against cancer (Sager 1991; Campisi 2013; de Magalhaes 2013). However, this has become increasingly untenable as a clear association has emerged between short telomeres and higher incidence of cancer (Rode et al. 2015). Considering also that many species not susceptible to cancer nevertheless are subject to mortality increase from cellular senescence (Mitteldorf 2013), we must regard cell senescence as a form of programmed aging that has persisted since the Cambrian explosion.

- Apoptosis in yeast cells under stress has been documented as an altruistic aging program (Fabrizio et al. 2004). Apoptosis continues to play a role in senescence of multicelled organisms including humans (Behl 2000; Marzetti and Leeuwenburgh 2006).

- An inverse association between fertility and life span is predicted by the Disposable Soma (Kirkwood 1977) and other theories of metabolic tradeoff. But this correlation is observed neither in animals (Ricklefs and Cadena 2007) nor in humans (Gavrilova et al. 2004; Mitteldorf 2010a, b).
These and other arguments for aging as a genetic program are reviewed in (Bredesen 2004; Mitteldorf 2004; de Magalhães and Church 2005; Mitteldorf 2010a, b; de Magalhães 2012; Goldsmith 2013; Pepper et al. 2013; Mitteldorf 2016).

\section{Programmed aging is inconsistent with the standard model of evolutionary genetics}

Historically, the idea that aging could be an evolutionary adaptation has been a non-starter because aging is the opposite of fitness, defined as individual reproductive success. If we believe that natural selection is in the business of maximizing some measure of reproductive potential (e.g. $\boldsymbol{r}$ or $\mathbf{R}_{\mathrm{o}}$ ), then evolution must always be toward higher fertilities and longer life spans, to the extent these are not in conflict.

The quantitative formulation on which this thinking is founded is not Darwin's, though it is called neoDarwinism. It was developed in the early twentieth Century by Sharpe and Lotka (1911) and formalized into a fully axiomatic mathematical system by Fisher (1930). Most theoretical evolutionists take it as gospel, but it is demonstrably false. There have been many counter-examples, in which a variety that has shorter life span, lower fertility, and worse survivability outcompetes a variety that is better in all these respects. An example of guppies in the river pools of Trinidad was documented by Reznick (Bryant and Reznick 2004). My favorite example is the Rocky Mountain Locust, a super-competitor that swarmed to cover hundreds of thousands of square kilometers of sky in the American mid-west a hundred years ago, denuded vast regions of every green leaf and blade of grass in its heyday. Although individually a super-competed, collectively, the Rocky Mountain Locust was a circular firing squad that drove itself into extinction within a few years. There are no surviving specimens today (Yoon 2002).

My contribution to this field has been a theoretical suggestion about why individual success in the Darwinian competition inevitably leads to a tragedy of the commons (Hardin 1968) that brings down the entire ecosystem. Natural selection at the ecosystem level is an efficient force in direct opposition to individual selection for reproductive profligacy. This changes everything we thought we knew about what constitutes fitness. In particular, it opens a window for 
selection of aging as an adaptation. What follows is a line of reasoning adapted from (Mitteldorf 2006).

Intuitively, we know that populations are subject to environmental feedback. If a population is lower than the carrying capacity, births exceed deaths, and the population grows. If a population is greater than the carrying capacity, deaths exceed births, and the population falls. We may expect a population out of equilibrium to smoothly approach its carrying capacity (Figs. 1, 2).

But every species is dependent on an ecosystem. The fox is dependent on the rabbit, and the rabbit depends on the grass. Crucially, the rate at which the grass grows is fixed by sunlight, and it cannot grow faster. But other species, higher up the food chain, evolve higher and higher growth rates according to Lotka's model. Increasing individual reproductive success has the collective effect of increasing the population growth rate, or exponential rate of increase.

Rabbits may evolve to grow their population faster than the grass can keep up. For most species that are not at the bottom trophic level, it is not difficult to evolve a faster reproductive rate, because there is a reservoir of food to be tapped. Tapping the food supply more deeply permits a faster growth rate in the predator, but the depleted prey population makes this a losing proposition, not just in the long run but even in a single generation. If collectively we abuse the ecosystem on which we depend, our children will starve.

This dynamic is reflected in the mathematics of the logistic equation. The plots in Figs. 1 and 2 were based on an exponential growth rate for the rabbits that is small compared to the grass. The ratio of the rabbits' growth rate to the growth rate of the grass is called the "chaos parameter", for reasons we may see in Figs. 3, 4, 5. When the rabbits grow at twice the rate of the grass, we see some oscillation about the carrying capacity.

When the ratio increases to 2.5 , this oscillation becomes more severe.

For ratios greater than about 2.59, the pattern ceases to be periodic, and fluctuations become increasingly wide and irregular.
Fig. 1 Logistic solution for population approaching steady state from above
Fig. 2 Logistic solution for population approaching steady state from below
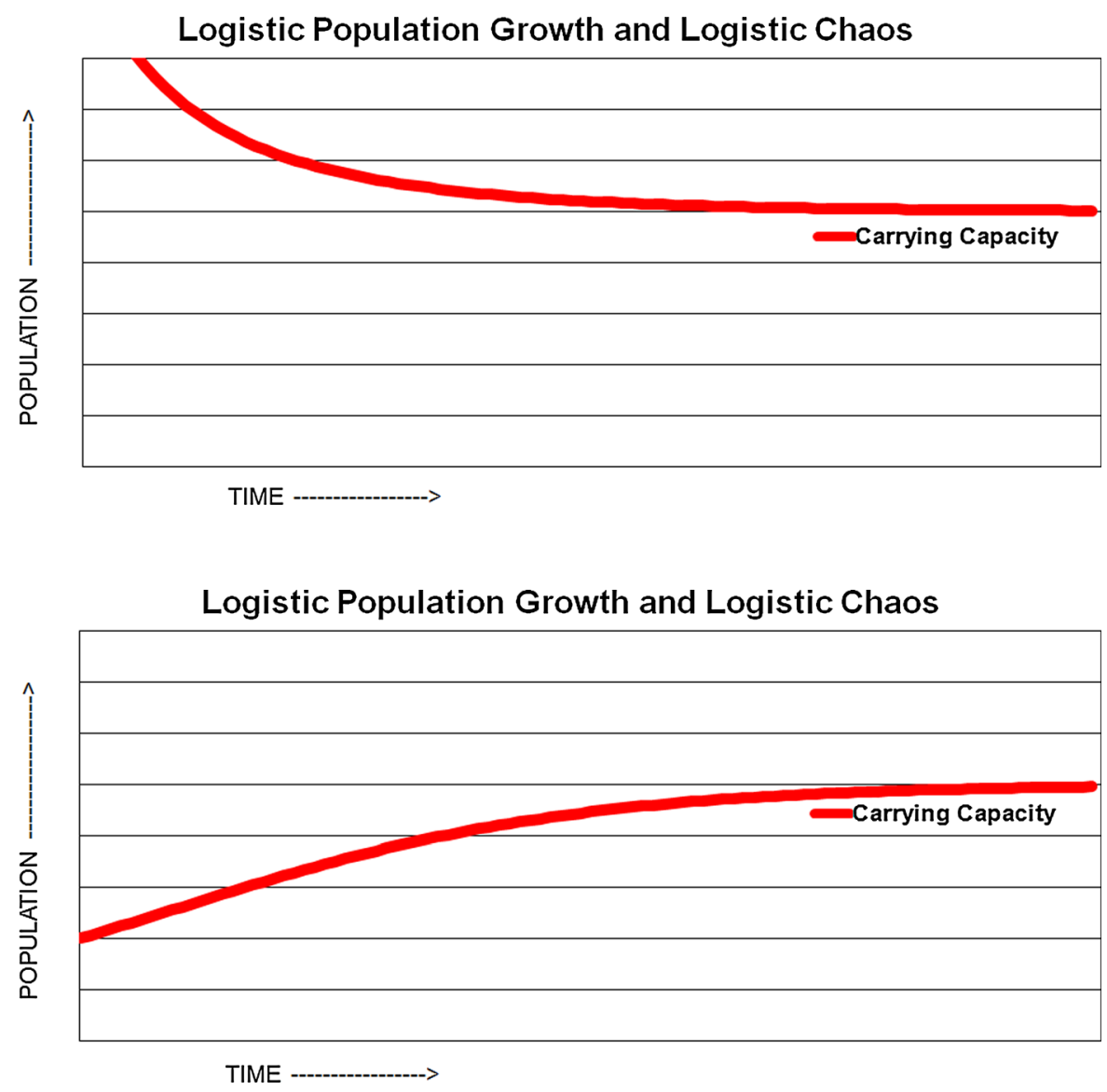
Fig. 3 Logistic growth for chaos parameter $=2$

Fig. 4 Logistic growth for chaos parameter $=2.5$

Fig. 5 Logistic growth for chaos parameter $=2.9$
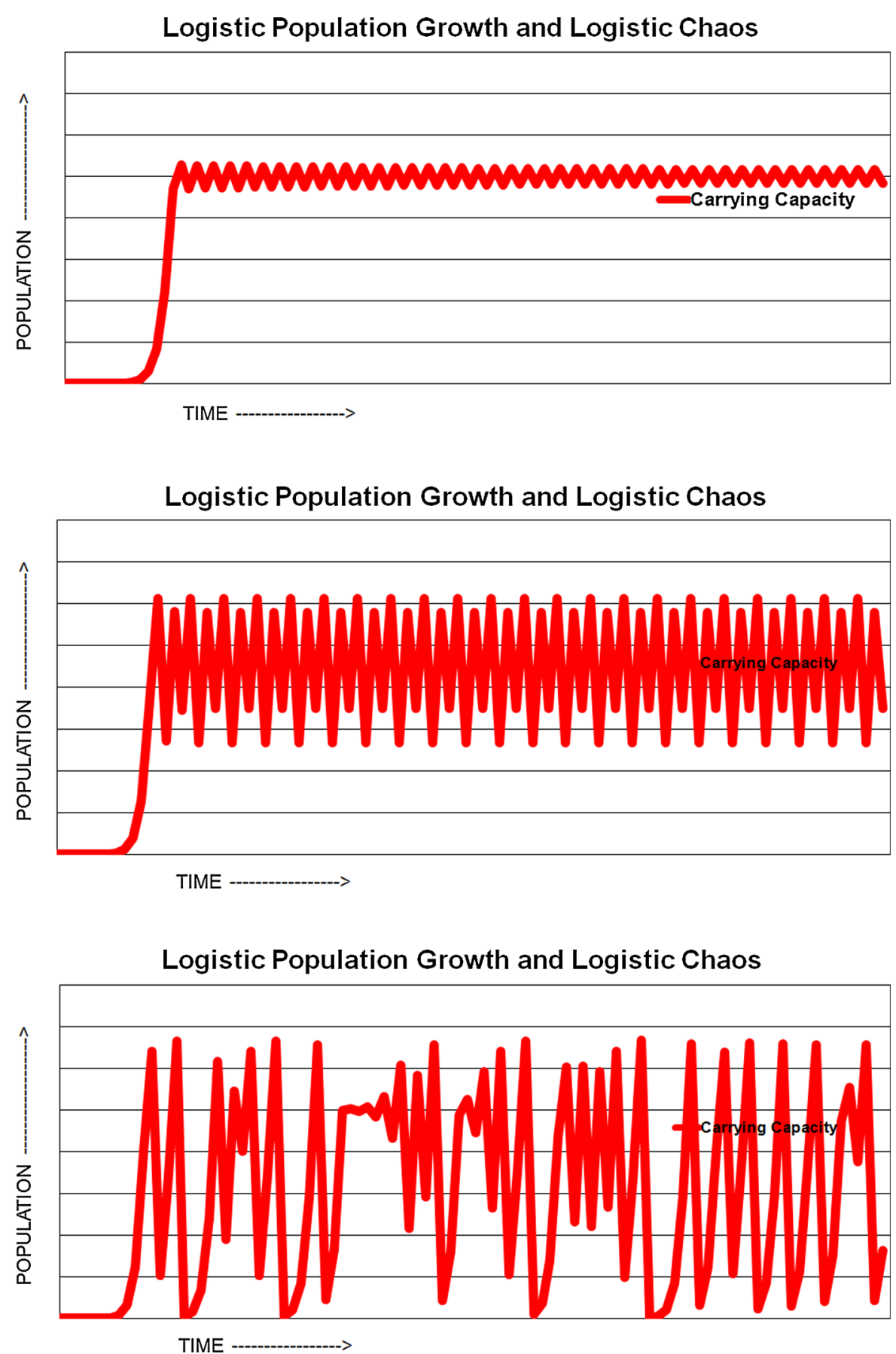

For values greater than 3 , the population drops to zero and, of course, cannot recover. The number 3 is a line in the sand only for mathematics. But there's no physiologic reason why reproduction rates can't get as high as 3 or 4 or 10 or 20. In fact, the reason that animals have evolved birth rates that are less than they are physically capable of and death rates that are higher than necessary is to avoid population chaos. Demographic chaos is a fast track to extinction.

Population dynamics is a very rapid and powerful force of Darwinian selection. For insect species, it can destroy a population in one season. With growth rates 
typical of mammals, it can wipe out an entire population in a single individual's lifetime. Such an event was documented in recent history, when reindeer were introduced to St Matthews Island in the Bering Sea in 1944. The reindeer were evolved for an environment where they were hunted by wolves, but $\mathrm{St}$ Matthews had no natural predators. The reindeer population grew exponentially for 18 years, then died off in a single winter (Klein 1968).

Population dynamics is a powerful evolutionary force at the group level, and it is working in direct opposition to individual selection for faster reproduction. This is why the 100-year old idea that natural selection maximizes individual reproductive success is wrong.

\section{A window for evolution of aging}

With the evolutionary imperative to maximize reproduction effective blunted, there is an opportunity for aging to evolve as an adaptation. Aging may evolve "opportunistically" for reasons that have nothing to do with population dynamics. Aging offers a selective advantage for population turnover (Martins 2011), contributes to evolvability (Mitteldorf and Martins 2014), and helps diversify the population to protect against infectious epidemics (Mitteldorf and Pepper 2009).

In addition to these "opportunistic" pathways, aging may evolve because of its direct benefit for preventing demographic extinctions. Aging stabilizes population dynamics by leveling out the death rate when the grass is thick and when the grass is sparse. Without aging, the entire adult population is uniformly strong, and deaths tend to be highly clustered in times of crowding, epidemics, and famine. Aging substitutes a steady stream of individual deaths, and protects against the overcrowding that leads to population collapse (Mitteldorf and Goodnight 2012).

\section{Biological clocks for aging}

Once the theoretical objections to programmed aging are answered and the empirical evidence is considered, the programmed aspects of aging come into focus. If aging proceeds under genetic control, it is probable that the body keeps a reference clock, or perhaps several redundant clocks to insure the body does not escape destruction, and to protect against evolutionary reversion to a non-aging phenotype.

Two biological clocks have been studied and documented in humans, the first based on telomere shortening and cell senescence; the second based on involution of the thymus. Telomere attrition has an ancient history as the only mode of senescence in onecelled ciliates (Clark 1999, 2004). In humans, telomere length of leukocytes is now a commercially available lab test. Since stem cells are replicating through a lifetime and very little telomeraseis exp ressed after the embryo stage, telomere length declines over a lifetime. For decades, this was known, but there was no indication whether telomere shortening had implications for aging mortality. Then in 2003, (Cawthon et al. 2003) used historic blood samples from a Salt Lake City hospital to demonstrate that telomere length is a strong predictor of age-adjusted mortality. The finding has been replicated in humans (Bischoff et al. 2005; Harris et al. 2006; Brouilette et al. 2007; Fitzpatrick et al. 2007; Kimura et al. 2008; Fyhrquist et al. 2011; Ma et al. 2011; Strandberg et al. 2011; Willeit et al. 2011) and also in mammals (Brümmendorf et al. 2002; McKevitt et al. 2002) and birds (Pauliny et al. 2006). There are two plausible mechanisms by which cellular senescence contributes to aging. First, the population of stem cells that replenish muscle, skin and immune cells is depleted by senescence, contributing to aging of these tissues. Second, cells with short telomeres are a source of inflammatory cytokines, with system-wide consequences far out of proportion to the number of affected cells (Baker et al. 2011).

The thymus is a gland in which T-cells are trained to distinguish self from invader. With age the thymus shrinks in size and becomes less functional, with consequences for the competence of the immune system as a whole. At advanced ages, T cells are prone to errors of Type 1 and Type 2. Type 1 errors allow invading microbes to escape undetected, with the result that the elderly have a heavier burden of infectious disease. In type 2 errors, healthy indigenous tissues are attacked in an autoimmune response, typical of arthritis and other diseases of old age.

Reasons to believe there is a third clock

Williams (1957) first articulated theoretical reasons to believe that aging should have evolved to be 
controlled by multiple independent factors, and his reasoning remains valid today.

Some animals suffer senescence even though their telomeres don't shorten with age. And some modes of aging in humans seem unlikely to be related to telomeres and immune function. For example, the brain ages though neuronal growth is not directly limited by short telomere or the state of the thymus.

A broader reason for suspecting the existence of a third, epigenetic aging clock comes from thinking about developmental biology. In growth, development and puberty, timing is exquisitely sensitive. It is widely believed that development is under control of gene expression, i.e., epigenetic programming. What clock tells the body when to secrete growth factors and when to stop, or when to initiate puberty with gonadotropic hormones? This remains an unanswered question in developmental biology. Ebling (2005) In recent years, it has become clear that gene expression is a strong function of age (de Magalhães et al. 2009; Zykovich et al. 2014). The fact that a separate clock has never been identified suggests that gene expression itself might be a clock. Time can be measured using a feedback loop, and gene expression provides such a loop:

- Epigenetic state of cells controls gene expression (including circulating hormones).

- Circulating hormones feed back to continually reprogram the epigenetic state of cells.

The existence of an epigenetic aging clock was independently suggested by Rando and Chang (2012), de Magalhães (2012), and Johnson et al. (2012).

\section{Parabiosis and factors in the blood}

Parabiosis is the surgical joining of two bodies so that they share a common circulatory flow. Heterochronic parabiosis is the joining of a young and old animal. Experiments were done with mice beginning in the nineteenth century, and in the 1950s, the field was renewed by the same Clive McCay et al. (1957) who discovered the life extension potential of caloric restriction in the 1930s.

The current wave of parabiosis experiments with mice grew from Rando's Stanford University laboratory, and several of his students in the early 2000s. The Conboys, Villeda, Wagers, and Wyss-
Coray today conduct parabiosis experiments in their own labs. The first promising experiment in this new wave was published in 2005 (Conboy et al. 2005), in which it was reported that impaired muscle and skin healing in an old mouse was rescued by exposure to blood from a young mouse. It was not the red or white blood cells that offered the benefit, but protein and RNA factors dissolved in the plasma. Intriguingly, gene expression was found to be broadly impacted, reverting to a more youthful profile.

These experiments established the possibility that old tissue could be rejuvenated by a young signaling environment. The next steps were to transfuse blood plasma from young to old mice, and to identify specific factors in the blood that are responsible for rejuvenation. Mayack et al. (2010) found that haematopoietic stem cells could be rejuvenated by a youthful profile of blood factors.

This work is very much in progress. Recently, a number of results have been published that make the epigenetic clock model look more plausible. Villeda (Bouchard and Villeda 2014) reports that infusion of young blood plasma reverses nerve damage, improves cognitive function in mouse model of alzheimer's disease. It has already become clear that there are both anti-aging factors that are under expressed and also pro-aging factors that are overexpressed in old mice. Among the anti-aging factors identified are GDF11, which promotes nerve and muscle growth (Katsimpardi et al. 2014) and oxytocin, which is necessary for muscle maintenance (Elabd et al. 2014). Among the pro-aging factors identified are TGF $\beta$ and $\mathrm{Nf} \kappa \mathrm{B}$, which promote inflammation (Conboy et al. 2005), and FSH which is associated with weight gain, osteoporosis, and some cancers (Merry and Holehan 1981; Bowles 1998).

Using algorithmic searches based on statistics alone, Horvath (Horvath 2013) has found combinations of DNA methylation sites that change so consistently with age that an accurate measure of functional age can be constructed. There is a great deal of consistency among different tissues and different donors. (Jones et al. 2015) makes a first pass at partitioning the difference in methylation patterns between stochastic change, which may be regarded as dysregulation, and consistent patterns, which may be regarded as programmed aging. 


\section{Future directions}

It is a fact that gene expression changes with age, and a reasonable hypothesis that gene expression controls some aging phenotypes. There is reason to hope that restoring the body to a youthful state of gene expression will rejuvenate the repair and growth faculties, stimulating the body to repair years of accumulated damage. We have seen that a few powerful transcription factors are capable of reprogramming the epigenetic state of chromatin, and this suggests a promising path for aging research.

For future medical applications, the existence of an epigenetic aging clock will do us little good if it is essentially complex, and must be re-programmed, one site at a time, with the epigenetic markers characteristic of youth.

But if we are fortunate, then some manageable number of circulating hormones and other blood factors will be discovered that can signal the body to return epigenetic programming to a more youthful state. If only because the prize is potentially so large, this possibility is a worthy focus for intensive research in the near future.

\section{References}

Baker DJ, Wijshake T, Tchkonia T, LeBrasseur NK, Childs BG, van de Sluis B, Kirkland JL, van Deursen JM (2011) Clearance of p16Ink4a-positive senescent cells delays ageing-associated disorders. Nature 479(7372):232-236

Behl C (2000) Apoptosis and alzheimer's disease. J Neural Trans 107(11):1325-1344

Bischoff C, Graakjaer J, Petersen HC, Jeune B, Bohr VA, Koelvraa S, Christensen K (2005) Telomere length among the elderly and oldest-old. Twin Res Hum Genet 8(5):425-432

Blagosklonny M (2010) Revisiting the antagonistic pleiotropy theory of aging. Cell Cycle 9(16):3151-3156

Bonduriansky R, Brassil CE (2002) Senescence: rapid and costly ageing in wild male flies. Nature 420(6914):377

Bouchard J, Villeda SA (2014) Aging and brain rejuvenation as systemic events. J Neurochem. doi:10.1111/jnc.12969

Bowles JT (1998) The evolution of aging: a new approach to an old problem of biology. Med Hypotheses 51(3):179-221

Bredesen DE (2004) The non-existent aging program: how does it work? Aging Cell 3(5):255-259

Bronikowski AM, Promislow DE (2005) Testing evolutionary theories of aging in wild populations. Trends Ecol Evol 20(6):271-273

Brouilette SW, Moore JS, McMahon AD, Thompson JR, Ford I, Shepherd J, Packard CJ, Samani NJ (2007) Telomere length, risk of coronary heart disease, and statin treatment in the West of Scotland Primary Prevention Study: a nested case-control study. Lancet 369(9556):107-114

Brümmendorf TH, Mak J, Sabo KM, Baerlocher GM, Dietz K, Abkowitz JL, Lansdorp PM (2002) Longitudinal studies of telomere length in feline blood cells: implications for hematopoietic stem cell turnover in vivo. Exp Hematol 30(10):1147-1152

Bryant MJ, Reznick D (2004) Comparative studies of senescence in natural populations of guppies. Am Nat 163(1):55-68

Calabrese EJ (2005) Toxicological awakenings: the rebirth of hormesis as a central pillar of toxicology. Toxicol Appl Pharmacol 204(1):1-8

Calabrese EJ, Baldwin LA (1998) Hormesis as a biological hypothesis. Environ Health Perspect 106(Supp 1):357-362

Campisi J (2013) Aging, cellular senescence, and cancer. Annu Rev Physiol 75:685

Cawthon RM, Smith KR, O'Brien E, Sivatchenko A, Kerber RA (2003) Association between telomere length in blood and mortality in people aged 60 years or older. Lancet 361(9355):393-395

Clark WR (1999) A means to an end: the biological basis of aging and death. Oxford University Press, New York, Oxford

Clark WR (2004) Reflections on an unsolved problem of biology: the evolution of senescence and death. Adv Gerontol 14:7-20

Conboy IM, Conboy MJ, Wagers AJ, Girma ER, Weissman IL, Rando TA (2005) Rejuvenation of aged progenitor cells by exposure to a young systemic environment. Nature 433(7027):760-764

Curtsinger JW, Fukui HH, Khazaeli AA, Kirscher A, Pletcher SD, Promislow DE, Tatar M (1995) Genetic variation and aging. Annu Rev Genet 29:553-575

de Magalhaes JP (2013) How ageing processes influence cancer. Nat Rev Cancer 13(5):357-365

de Magalhães JP (2012) Programmatic features of aging originating in development: aging mechanisms beyond molecular damage? FASEB J 26(12):4821-4826

de Magalhães JP, Church GM (2005) Genomes optimize reproduction: aging as a consequence of the developmental program. Physiology 20(4):252-259

de Magalhães JP, Curado J, Church GM (2009) Meta-analysis of age-related gene expression profiles identifies common signatures of aging. Bioinformatics 25(7):875-881

Ebling FJ (2005) The neuroendocrine timing of puberty. Reproduction 129(6):675-683

Elabd C, Cousin W, Upadhyayula P, Chen RY, Chooljian MS, Li J, Kung S, Jiang KP, Conboy IM (2014) Oxytocin is an age-specific circulating hormone that is necessary for muscle maintenance and regeneration. Nat Commun 5:4082

Fabrizio P, Battistella L, Vardavas R, Gattazzo C, Liou LL, Diaspro A, Dossen JW, Gralla EB, Longo VD (2004) Superoxide is a mediator of an altruistic aging program in Saccharomyces cerevisiae. J Cell Biol 166(7):1055-1067

Fisher RA (1930) The genetical theory of natural selection. The Clarendon Press, Oxford

Fitzpatrick AL, Kronmal RA, Gardner JP, Psaty BM, Jenny NS, Tracy RP, Walston J, Kimura M, Aviv A (2007) Leukocyte 
telomere length and cardiovascular disease in the cardiovascular health study. Am J Epidemiol 165(1):14-21

Flatt T (2009) Ageing: diet and longevity in the balance. Nature 462(7276):989-990

Fyhrquist F, Silventoinen K, Saijonmaa O, Kontula K, Devereux RB, de Faire U, Os I, Dahlof B (2011) Telomere length and cardiovascular risk in hypertensive patients with left ventricular hypertrophy: the LIFE study. J Hum Hypertens 25(12):711-718

Gavrilova NS, Gavrilov LA, Semyonova VG, Evdokushkina GN (2004) Does exceptional human longevity come with a high cost of infertility? Testing the evolutionary theories of aging. Ann N Y Acad Sci 1019:513-517

Goldsmith TC (2013) The evolution of aging. Annapolis, Azinet

Guarente L, Kenyon C (2000) Genetic pathways that regulate ageing in model organisms. Nature 408(6809):255-262

Hanson RW, Hakimi P (2008) Born to run; the story of the PEPCK-Cmus mouse. Biochimie 90(6):838-842

Hardin G (1968) The tragedy of the commons. Science 162:1243-1248

Harris SE, Deary IJ, Maclntyre A, Lamb KJ, Radhakrishnan K, Starr JM, Whalley LJ, Shiels PG (2006) The association between telomere length, physical health, cognitive ageing, and mortality in non-demented older people. Neurosci Lett 406(3):260-264

Horvath S (2013) DNA methylation age of human tissues and cell types. Genome Biol 14(10):R115

Johnson AA, Akman K, Calimport SR, Wuttke D, Stolzing A, de Magalhães JP (2012) The role of DNA methylation in aging, rejuvenation, and age-related disease. Rejuvenation Res 15(5):483-494

Jones MJ, Goodman SJ, Kobor MS (2015) DNA methylation and healthy human aging. Aging cell. (in press)

Jones OR, Scheuerlein A, Salguero-Gomez R, Camarda CG, Schaible R, Casper BB, Dahlgren JP, Ehrlen J, Garcia MB, Menges ES, Quintana-Ascencio PF, Caswell H, Baudisch A, Vaupel JW (2014) Diversity of ageing across the tree of life. Nature 505(7482):169-173

Katsimpardi L, Litterman NK, Schein PA, Miller CM, Loffredo FS, Wojtkiewicz GR, Chen JW, Lee RT, Wagers AJ, Rubin LL (2014) Vascular and neurogenic rejuvenation of the aging mouse brain by young systemic factors. Science 344(6184):630-634

Kenyon C (2001) A conserved regulatory system for aging. Cell 105(2):165-168

Kimura M, Hjelmborg, JVB, Hjelmborg JVB, Gardner JP, Bathum L, Brimacombe M, Lu X, Christiansen L, Vaupel JW, Aviv A, Christensen K (2008) Telomere length and mortality: a study of leukocytes in elderly Danish twins. Am J Epidemiol 167(7):799-806

Kirkwood T (1977) Evolution of aging. Nature 270:301-304

Kirkwood TB (2005) Understanding the odd science of aging. Cell 120(4):437-447

Klein DR (1968) The introduction, increase, and crash of reindeer on St Matthew Island. J Wildl Manag 32(2):350-367

Ma H, Zhou Z, Wei S, Liu Z, Pooley KA, Dunning AM, Svenson U, Roos G, Hosgood HD III, Shen M, Wei Q (2011) Shortened telomere length is associated with increased risk of cancer: a meta-analysis. PLoS ONE 6(6):e20466

Martins AC (2011) Change and aging senescence as an adaptation. PLoS ONE 6(9):e24328
Marzetti E, Leeuwenburgh C (2006) Skeletal muscle apoptosis, sarcopenia and frailty at old age. Exp Gerontol 41(12):1234-1238

Masoro EJ (2003) Subfield history: caloric restriction, slowing aging, and extending life. Science's SAGE KE 2003(8):2

Masoro EJ (2005) Overview of caloric restriction and ageing. Mech Ageing Dev 126(9):913-922

Masoro EJ (2007) The role of hormesis in life extension by dietary restriction. Interdiscip Top Gerontol 35:1-17

Mayack SR, Shadrach JL, Kim FS, Wagers AJ (2010) Systemic signals regulate ageing and rejuvenation of blood stem cell niches. Nature 463(7280):495-500

McCay CM, Pope F, Lunsford W, Sperling G, Sambhavaphol P (1957) Parabiosis between old and young rats. Gerontology 1(1):7-17

McKevitt TP, Nasir L, Devlin P, Argyle DJ (2002) Telomere lengths in dogs decrease with increasing donor age. J Nutr 132(6):1604S-1606S

Medawar PB (1952) An unsolved problem of biology. Published for the college by H. K. Lewis, London

Merry BJ, Holehan AM (1981) Serum profiles of LH, FSH, testosterone and 5 alpha-DHT from 21 to 1000 days of age in ad libitum fed and dietary restricted rats. Exp Gerontol 16(6):431-444

Mitteldorf J (2001) Can experiments on caloric restriction be reconciled with the disposable soma theory for the evolution of senescence? Evol Int J Org Evol 55(9):1902-1905 discussion 1906

Mitteldorf J (2004) Aging selected for its own sake. Evol Ecol Res 6:1-17

Mitteldorf J (2006) Chaotic population dynamics and the evolution of aging: proposing a demographic theory of senescence. Evol Ecol Res 8:561-574

Mitteldorf J (2010a) Evolutionary origins of aging. Approaches to the control of aging: building a pathway to human life extension. In: Fahy GM, West MD, Coles LS, Harris SB (eds). New York, Springer, pp 87-126

Mitteldorf J (2010b) Female fertility and longevity. Age (Dordr) $32: 79-84$

Mitteldorf J (2013) Telomere biology: cancer firewall or aging clock? Biochem (Moscow) 78(9):1054-1060

Mitteldorf J (2016). Aging is a group-selected adaptation: theory, evidence, and medical implications, CRC Press

Mitteldorf J, Goodnight C (2012) Post-reproductive life span and demographic stability. Oikos 121(9):1370-1378

Mitteldorf J, Martins AC (2014) programmed life span in the context of evolvability. Am Nat 184(3):289-302

Mitteldorf J, Pepper J (2009) Senescence as an adaptation to limit the spread of disease. J Theor Biol 260(2):186-195

Nussey DH, Froy H, Lemaitre JF, Gaillard JM, Austad SN (2012) Senescence in natural populations of animals: widespread evidence and its implications for bio-gerontology. Ageing Res Rev 12(1):214-225

Pauliny A, Wagner RH, Augustin J, Szep T, Blomqvist D (2006) Age-independent telomere length predicts fitness in two bird species. Mol Ecol 15(6):1681-1687

Pepper J, Shelton D, Rashidi A, Durand P (2013) Are internal, death-promoting mechanisms ever adaptive. J Phylogen Evol Biol 1(113):2 
Rando TA, Chang HY (2012) Aging, rejuvenation, and epigenetic reprogramming: resetting the aging clock. Cell 148(1):46-57

Ricklefs R (1998) Evolutionary theories of aging: confirmation of a fundamental prediction, with implications for the genetic basis and evolution of life span. Am Nat 152:24-44

Ricklefs RE, Cadena CD (2007) Lifespan is unrelated to investment in reproduction in populations of mammals and birds in captivity. Ecol Lett 10(10):867-872

Rode L, Nordestgaard BG, Bojesen SE (2015) Peripheral blood leukocyte telomere length and mortality among 64637 individuals from the general population. J Natl Cancer Inst 107(6):djv074

Sager R (1991) Senescence as a mode of tumor suppression. Environ Health Perspect 93:59-62

Sharpe FRL, Lotka AJ (1911) A problem in age-distribution. Philos Mag 21:435-438

Spitze K (1991) Chaoborus predation and life history evolution in Daphnia pulex: temporal pattern of population diversity, fitness, and mean life history. Evolution 45(1):82-92

Stearns SC (2000) Life history evolution: successes, limitations, and prospects. Naturwissenschaften 87(11):476-486
Strandberg TE, Saijonmaa O, Tilvis RS, Pitkala KH, Strandberg AY, Miettinen TA, Fyhrquist F (2011) Association of telomere length in older men with mortality and midlife body mass index and smoking. J Gerontol A Biol Sci Med Sci 66(7):815-820

Weindruch R, Walford RL (1988) Retardation of aging and disease by dietary restriction. CC Thomas, Springfield

Willeit P, Willeit J, Kloss-Brandstatter A, Kronenberg F, Kiechl S (2011) Fifteen-year follow-up of association between telomere length and incident cancer and cancer mortality. JAMA 306(1):42-44

Williams G (1957) Pleiotropy, natural selection, and the evolution of senescence. Evolution 11:398-411

Yoon CK (2002) Looking back at the days of the locust. New York Times, New York

Zykovich A, Hubbard A, Flynn JM, Tarnopolsky M, Fraga MF, Kerksick C, Ogborn D, MacNeil L, Mooney SD, Melov S (2014) Genome-wide DNA methylation changes with age in disease-free human skeletal muscle. Aging Cell 13(2):360-366 